\title{
POLÍTICAS DA PSICOLOGIA: HISTÓRIAS E PRÁTICAS DAS ASSOCIAÇÕES PROFISSIONAIS (CRP E SPESP) DE SÃO PAULO, ENTRE A DITADURA E A REDEMOCRATIZAÇÃO DO PAÍS
}

\author{
Domenico Uhng Hur
}

\begin{abstract}
Resumo: O objetivo do nosso trabalho é discutir a história e práticas das associações profissionais com objetivos políticos da psicologia entre o regime militar e o processo de redemocratização do país. Na pesquisa entrevistamos seis ex-participantes de diretorias dessas entidades e fizemos a análise documental de 1076 atas do CRP e do SPESP. Constatamos que no início houve um alinhamento político das entidades com a ditadura militar, quando estas se recusaram a participar de movimentos críticos ao regime e quando premiaram com o título de psicólogo honorário representantes da ditadura militar. No fim da década de 1970, período em que os movimentos sociais ressurgem no Brasil, uma oposição com ideologia de esquerda se organiza e vence as eleições nas duas entidades. Assumem maior caráter político e contribuem com movimentos sociais do país, como a fundação da CUT e o movimento das Diretas Já.
\end{abstract}

Palavras-chave: História da psicologia. Ditadura militar. Associações profissionais. Psicologia política.

Os estudos sobre a história da Psicologia no Brasil tradicionalmente centramse na apreensão da Psicologia enquanto "Ciência", na leitura do desenvolvimento 
das escolas de pensamento, das linhas teóricas, dos campos de atuação, etc. (Antunes, 1998; Massimi \& Guedes, 2004), sendo raros os estudos que apreendem a construção dessa disciplina a partir do seu viés político, por exemplo, das práticas e histórias das associações profissionais de psicólogos com objetivos eminentemente políticos.

Compreendemos que a Psicologia é uma disciplina construída socialmente a partir da ação de psicólogos, pesquisadores e de suas associações profissionais, mas infelizmente há poucas publicações sobre o tema, por exemplo: material das próprias entidades (Conselho Regional de Psicologia, 1994; Sindicato dos Psicólogos no Estado de São Paulo, 1975; Sindicato dos Psicólogos no Estado de São Paulo \& Conselho Regional de Psicologia, 1984), alguns livros (Bock, 1999; Mello, 1977), artigos (Hur, 2007, 2009), algumas dissertações de mestrado (Bock, 1991; Hur, 2005), etc., então as principais fontes de dados dessa História são os documentos, atas, correspondências, relatórios e jornais das próprias associações.

Talvez esse fato decorra da "jovialidade" da história da Psicologia enquanto disciplina no Brasil, em que seus estudos têm cerca de trinta anos; mas também hipotetizamos que esse fato pode expressar o afastamento da Psicologia tradicional do político, em que se interessa mais pela história da constituição de ideias psicológicas do que pelas práticas concretas das instituições políticas da Psicologia, assumindo assim uma postura menos implicada com as questões sociais e políticas da atualidade e de sua história.

Dessa forma, nosso objetivo neste artigo é realizar uma discussão acerca do histórico de algumas práticas de associações profissionais de psicólogos com objetivos políticos do estado de São Paulo; de como surgiram, como se portaram durante a ditadura militar e no processo de redemocratização do país. As associações dos psicólogos portaram-se como instituições disciplinares, conforme o entendimento de Foucault? Ou então poderíamos dizer que as práticas assumidas corresponderam às de um movimento social de psicólogos? Consideramos que a relevância dessa discussão se dá pela necessidade de refletirmos sobre a organização dos psicólogos, suas práticas políticas e sua relação com a sociedade e o Estado. Para tanto, colocamos algumas perguntas: Quais foram os posicionamentos dessas entidades na história brasileira? Elas tiveram uma prática emancipadora ou perpetuadora das relações de poder instituídas no país?

Consideramos que realizar um histórico das práticas políticas é poder desvelar o que está encoberto sob o discurso oficial e instituído. $\mathrm{O}$ pensador M. Foucault nos ensina que no Império Romano a história tinha como função garantir o não esquecimento, a lei e a manutenção do poder instituído, então "a nova história que aparece vai ter de desenterrar alguma coisa que foi escondida, e que foi escondida não somente porque menosprezada, mas também porque, ciosa, deliberada, maldosamente, deturpada e disfarçada" (Foucault, 1999, p. 83). 
No fundo, o que a nova história quer mostrar é que o poder, os poderosos, os reis, as leis esconderam que nasceram no acaso e na injustiça das batalhas... Portanto, o papel da história será o de mostrar que as leis enganam, que os reis mascaram, que o poder ilude e que os historiadores mentem. Não será, portanto, uma história da continuidade, mas uma história da decifração, da detecção do segredo, da devolução da astúcia, da reapropriação de um saber afastado ou enterrado. Será a decifração de uma verdade selada. (Foucault, 1999, p. 84)

Em convergência com o enunciado foucaultiano, "a análise institucional está cada vez mais interessada pela história como conjunto de técnicas de rechaço, de ocultamento, de mistificação - condições de nascimento e sobrevivência das instituições" (Lourau, 2004, p. 144). Então, na própria história da Psicologia já encontramos aspectos encobertos, pois no que se refere à relação entre Psicologia e sociedade, atualmente há o imaginário social de que a Psicologia é emancipadora, de que a Psicologia tem uma prática contributiva para o progresso da sociedade, dos sujeitos e dos coletivos, vide, por exemplo, o slogan do Conselho Federal de Psicologia muito veiculado na década de 1990,"Psicologia e compromisso social." Esse é o imaginário difundido, de que a Psicologia porta uma prática positiva. Todavia, ao investigarmos a história da Psicologia, constatamos que no período colonial do Brasil, os conhecimentos psicológicos eram utilizados como saberes que auxiliaram na colonização e catequização dos índios (Massimi, 1990), ou seja, os saberes psi atuavam num processo de normalização (Foucault, 1984), disciplinando o povo autóctone através das normas dos europeus colonizadores. Então, a Psicologia em seus primórdios no país estava a serviço de uma elite social e assumia uma função coercitiva, tornando-se um instrumento de dominação e disciplinarização.

No fim do século XIX, quando as universidades foram criadas no país, a Psicologia continuou a ser utilizada da mesma forma, com o fim de dominação-doutrinação (Pessotti, 1998). Por exemplo, podemos citar o caso do massacre da comunidade de Canudos, de Antônio Conselheiro, no qual os saberes psicológicos, em conformidade com os interesses do Estado, atestaram que esse movimento social derivava-se de uma patologia psíquica, tanto da liderança, como dos participantes. Dessa forma, reduziu-se a liderança de Antonio Conselheiro a uma psicopatologia, a um comportamento anormal (fora da norma), para assim deslegitimar o movimento popular. Os conhecimentos psicológicos novamente tornaram-se instrumentos de uma elite dominadora, prestando um serviço e criando uma justificação para o Estado e para as classes dominantes da época, com o uso das forças armadas, exterminarem a comunidade (Macedo \& Maestri, 2004; Rodrigues, 1939). Tal conhecimento foi utilizado sob a égide do discurso da neutralidade, pois a Psicologia, sendo"neu- 
tra ${ }^{11,}$, produzia um regime de verdade, um discurso científico legitimado socialmente, constituindo assim normas sociais (Foucault, 1979), ou seja, produzindo o que é normal e o que é desvio e patologia, o que é regularidade e irregularidade. Portanto, as práticas psicológicas assumem posicionamentos políticos, tais como nossas entidades de classe.

Para discutir a atuação política das associações de Psicologia, escoIhemos investigar a história de duas entidades para a realização de nossa pesquisa: o Conselho Regional de Psicologia (CRP) e o Sindicato dos Psicólogos do Estado de São Paulo (SPESP) ${ }^{2}$. Consideramos que no âmbito da Psicologia de São Paulo são as que apresentam maior atuação política e canalizam as reivindicações dos psicólogos nas lutas sociais. Também abordaremos a associação que deu origem às duas, que foi a Associação Profissional dos Psicólogos do Estado de São Paulo - APPESP.Desse modo, pretendemos apresentar uma história da Psicologia a partir do olhar de suas associações políticas.

Realizamos nossa pesquisa através de revisão bibliográfica da literatura sobre o tema, análise documental de todas as atas e jornais do CRP, do SPESP e da APPESP, entre os anos de 1969 e 1991, o que totalizou 1076 atas e 163 boletins informativos, e a realização de entrevistas com seis ex-membros das diretorias dessas associações ${ }^{3}$.Entrevistamos dois membros participantes da década de 1970, identificados a uma prática política conservadora, e quatro membros participantes nas décadas de 1980 e 1990, identificados à esquerda política.

Na análise documental (Bardin, 1977; Mann, 1983) privilegiamos os documentos primários, como as atas e as entrevistas, enquanto utilizamos os documentos secundários, como os jornais e boletins, apenas para complementar nossas informações. Em nossa leitura dos fatos históricos, privilegiamos a utilização do que o socioanalista René Lourau chama de analisadores históricos. Os analisadores são acontecimentos sociais que são autoenunciativos da problemática em questão, não necessitam ser interpretados, pois ao emergirem já operam uma espécie de análise institucional, "é o analisador que realiza a análise" (Lourau, 2004, p. 69). EscoIhemos então para o artigo analisadores sociais que expressam o funcio-

1 Sabemos que nenhuma prática é neutra, pois sempre uma ciência, uma prática, está implicada com seu "objeto" e campo de investigação (Lourau, 2004).

2 No decorrer do artigo, utilizaremos as siglas das entidades, por exemplo: Conselho Regional de Psicologia de São Paulo - CRP, Sindicato dos Psicólogos no Estado de São Paulo - SPESP, Associação Profissional dos Psicólogos do Estado de São Paulo - APPESP, Conselho Federal de Psicologia - CFP, Sociedade de Psicologia de São Paulo - SPSP e Associação Brasileira dos Psicólogos - ABP.

3 Os entrevistados foram Waldecy Alberto Miranda, Suzy Vijande Cambraia, Ghislaine Gliosce da Silva, Odette Godoy Pinheiro, Marlene Guirado e Luis Humberto Sivieri. 
namento das entidades, suas práticas sociais, por exemplo, o analisador relacionado às manifestações contra o assassinato de Wladimir Herzog, para refletir sobre as práticas políticas das associações profissionais dos psicólogos.

Com a sistematização e quantificação dos dados presentes nas atas, também organizamos algumas tabelas e gráficos para auxiliar na visualização de determinada prática. Sistematizamos todos os temas discutidos em cada reunião e verificamos sua incidência nas pautas das reuniões por semestre. Neste artigo apresentamos três gráficos.

Para tanto, nosso texto está organizado da seguinte forma: primeiro, realizamos breve problematização sobre a regulamentação da profissão Psicologia e a criação de suas entidades; segundo, as práticas políticas das associações na década de 1970; terceiro, as práticas na década de 1980 e, para finalizar, considerações gerais sobre o processo.

\section{A criação da profissão e das entidades dos psicólogos}

Para a constituição das associações profissionais de Psicologia foi necessária uma etapa inicial, que foi a institucionalização da profissão do psicólogo no Brasil, através do reconhecimento do Estado, via promulgação da Lei 4.119 de 27 de agosto de 1962, que rege a profissão do psicólogo.Tal lei foi aprovada após amplos debates e articulações políticas (Hur, 2007) organizadas por associações de cunho acadêmico-científico da Psicologia, tal como a Sociedade de Psicologia de São Paulo - SPSP - e a Associação Brasileira dos Psicólogos (ABP), criadas respectivamente em 1945 e 1954 pela psicóloga e professora da Universidade de São Paulo Annita de Castilho Marcondes e Cabral ${ }^{4}$.

Vale citar que na lei se encontram aspectos de caráter normalizador, como no artigo 13, sobre as funções privativas do psicólogo, em que constam quatro itens: diagnóstico psicológico, orientação psicopedagógica, orientação e seleção profissional e a alínea d, solucionar problemas de ajustamento. Então, na Lei, na alínea d, está prevista a ação do psicólogo enquanto normalizadora do comportamento, na qual ele deve solucionar os problemas de desvio e ajustar o sujeito, o grupo, a coletividade, num determinado padrão de uma suposta normalidade. Na Lei fica explícito tal caráter normalizador da profissão do psicólogo, que funciona tal como um mecanismo disciplinar (Foucault, 1984), que produz um padrão de normalidade, ditado pelos padrões dos grupos sociais dominantes. Ou seja, por Lei a Psicologia prossegue sendo um instrumento de normalização social. 
Os psicólogos que criaram a Lei 4.119/62 também propuseram artigos sobre seus órgãos fiscalizadores, os Conselhos de Psicologia, que regulamentariam e fiscalizariam o exercício profissional, no intuito de defender a profissão. Mas ao se publicar a Lei, a parte dos conselhos profissionais foi suprimida, ou seja, tudo que se referia aos conselhos foi retirado do texto. O primeiro presidente do CRP, W. Miranda (Hur, 2005), afirmou que o Estado tinha receio da organização da sociedade civil, então suprimiu essa parte da Lei, inviabilizando assim a organização dessas associações, concedendo a Lei 4.119, mas não os órgãos regulamentadores da Psicologia.

A Lei 4.119/62 é fruto de uma mobilização da década de 1950, contudo os psicólogos apenas voltaram a se mobilizar para instituir os conselhos em 1969, após o Ato Institucional no 5 - Al-5-, num momento de acirramento da repressão política no país, na época em que a violência do Estado foi a mais intensa na história brasileira. O país sofreu um golpe de Estado organizado por dirigentes militares e grupos conservadores da elite civil em 31 de março e $1^{\circ}$ de abril de 1964 sob a justificativa de deter o crescimento e a tomada de poder da esquerda política, instaurando-se assim uma ditadura militar (Gaspari, 2002). Houve intensa perseguição e prisão dos opositores políticos, cassação de direitos políticos, reforma e aposentadoria de militares (da oposição) e intelectuais, proibição da mobilização dos movimentos sociais, sendo a sociedade civil controlada e vigiada. Então no período da ditadura a participação política e os movimentos sociais foram duramente proibidos e reprimidos (Skidmore, 1998). No entanto, contraditoriamente é nesse período ditatorial que os psicólogos se organizam para criar os conselhos; os psicólogos voltam a se reorganizar justamente quando há um refluxo e uma intensa repressão aos movimentos sociais. A organização dos psicólogos não foi feita como um movimento social, reivindicador, e sim numa ação institucionalizada, direta, com os representantes do Estado da ditadura. Dois psicólogos ligados à ABP visitaram o ministro do Trabalho em 1969 solicitando a criação dos conselhos de Psicologia. Miranda (Hur, 2005) conta que o ministro respondeu que se a categoria queria ter seus conseIhos, ela deveria primeiro mostrar que está organizada, ou seja, antes de assumir o Conselho, organizar o Sindicato. Então os psicólogos deveriam criar um Sindicato atrelado ao Estado da ditadura para mostrar que a categoria estava "organizada" e consequentemente não representaria um perigo político para o regime instituído. Provavelmente o interesse do Governo militar não era ver a categoria organizada, mas sim ter uma categoria profissional atrelada a seus interesses políticos e que não iria se constituir como inimiga de seu Governo opressivo. Então, após tal organização, teria o direito de ter a Lei do Conselho Profissional aprovada.

Dessa forma, as Sociedades e Associações de Psicologia se organizaram. A SPSP e a ABP, no fim de 1969, tomaram a iniciativa de fundar a 
Associação Profissional dos Psicólogos do Estado de São Paulo - APPESP -, que foi o protótipo do Sindicato. Criaram a associação e com ela passaram a agremiar os psicólogos, em assuntos relativos à defesa da profissão, principalmente na questão dos exames psicotécnicos e de testes como o PMK - Psicodiagnóstico Miocinético - para serem utilizados na obtenção da carteira de habilitação de motorista. A atuação da APPESP estava apenas ligada às questões técnicas para a consolidação da profissão, sendo muitas das práticas diretamente ligadas à defesa do exame psicotécnico, por representar significativo mercado de trabalho para o psicólogo. Consideramos que a APPESP teve uma ação corporativista, em que o centro de sua preocupação era com a defesa do campo de atuação profissional do psicólogo.

A APPESP teve um trabalho direto com políticos no Congresso, com deputados e senadores, para aprovar a Lei dos Conselhos. Em nossa análise documental não encontramos registro de nenhum conflito ou estranhamento entre as associações de Psicologia e o Estado ditatorial. Dessa forma, em 20 de dezembro de 1971 foi aprovada a Lei 5.766, que dispõe sobre os Conselhos Profissionais de Psicologia, que estipula a criação do Conselho Federal de Psicologia (CFP) e mais sete conselhos regionais. No entanto, a instalação dos conselhos só ocorreu entre dois e três anos depois.

Em 1973, a APPESP conseguiu a associação de um terço dos psicólogos de São Paulo; duzentos profissionais. Ao conseguir esse número obteve a carta sindical do ministro do Trabalho. Então, nesse ano foi criado oficialmente o Sindicato dos Psicólogos no Estado de São Paulo - SPESP - representando a organização da categoria. O CFP apenas foi instalado em 1973 e os Conselhos Regionais na metade do ano de 1974.

O CRP e o Sindicato na década de 1970: uma filiação ao Estado da ditadura

O CRP tinha como objetivos a fiscalização e a disciplinarização do exercício profissional, enquanto a entidade sindical a representação dos psicólogos. Entretanto, mesmo com atribuições distintas, em que uma aparece como instituição disciplinar do Estado e a outra, como representação dos psicólogos, tiveram uma atuação conjunta. Praticamente compuseram um mesmo grupo e assumiram práticas eminentemente corporativistas, em que operaram uma cisão explícita entre a atuação profissional e política; sempre afirmaram que a própria atuação era ligada à profissão e não à política. Seja nas atas ou nas entrevistas (Cambraia e Miranda), afirmava-se que não se fazia política (Hur, 2005).

Temos um analisador social (Lourau, 2004) para ilustrar nossa afirmação. Em 1975, movimentos sociais organizados, movimentos huma- 
nistas e figuras históricas da Psicologia brasileira, como Madre Cristina Maria do Instituto Sedes Sapientiae, contataram o SPESP convidando-o a participar de manifestação pública pelos direitos humanos contra o assassinato do jornalista Wladimir Herzog, que foi morto em sessão de tortura nos porões do DOPS - Departamento de Operações Políticas e Sociais -, a polícia especializada da ditadura militar. A diretoria decidiu não participar desse movimento com uma justificativa corporativista, de que Wladimir Herzog não era psicólogo, era jornalista, e também porque esse tipo de atuação política fugia das atribuições contidas em estatuto, visto que as atribuições estatutárias do Sindicato eram de defesa à categoria dos psicólogos e não envolvimento em assuntos estranhos ao Estado, ou seja, a não participação em lutas políticas. Decidiram então não apoiar esse movimento de luta pelos direitos humanos e contra a opressão violenta da ditadura (SPESP, 1975, p.40/1). Dessa forma, a partir dessa justificativa corporativista, afastaram-se de qualquer postura política crítica ao Estado ditatorial, não se posicionando assim contra os arbítrios do Estado frente aos direitos humanos.

As associações e os entrevistados Cambraia e Miranda (Hur, 2005) afirmaram se afastar dos assuntos políticos, no entanto, o CFP, que era formado por muitos membros do CRP de São Paulo, concedeu o diploma de psicólogo honorário ao presidente E. G. Médici, que foi o ditador mais sanguinário do regime militar brasileiro, ao presidente E. Geisel e aos respectivos ministros do Trabalho. Então, além das associações da Psicologia não questionarem a ordem instituída e as políticas do Estado em relação à extrema violência e repressão, ratificaram as práticas políticas do Estado da ditadura, brindando aos presidentes e ministros tal homenagem (CRP, 1994). Por mais que afirmassem que sua atuação não era política, é evidente que há um posicionamento político ali presente e por mais que afirmassem nas entrevistas (Cambraia e Miranda citados por Hur, 2005) que a ditadura nunca influiu nas entidades, esses atos denotam não só o afastamento de uma postura crítica perante o Estado, mas também uma aliança. Por outro lado, entendemos que um questionamento direto sobre o regime militar poderia trazer prejuízos pessoais, como perseguição, prisão, tortura, etc. Contudo, homenageá-los com o diploma de psicólogo honorário é o analisador de que as associações legitimaram o regime político. Coincidência ou não, um fato relevante é que no final da década de 1970, tanto no CRP como no Sindicato, os presidentes eram militares (CRP, 1994).

Como assumiam uma atuação supostamente não política, focalizaram sua atuação na defesa da profissão, principalmente na defesa dos exames psicotécnicos, tal como a gestão do Sindicato de 1977-1979, que praticamente apenas discutiu os psicotécnicos em suas reuniões, seja nas discussões internas ou com o Departamento de Trânsito - DETRAN - e o Conselho Nacional de Trânsito - CONTRAN. Discutiu-se muito mais os 
exames psicotécnicos do que questões, por exemplo, do psicólogo no funcionalismo público. Abaixo no gráfico 1 temos a incidência de temas discutidos relacionados aos psicólogos por semestre nas reuniões do SPESP na gestão 1977-1979. Registramos através da leitura de todas as atas dessa gestão quatro temas: o psicólogo no funcionalismo público, os exames psicotécnicos, a tabela de honorários e o piso salarial do psicólogo. Como podemos claramente observar, a discussão sobre os exames psicotécnicos (barras de cor negra) adquiriu predominância, enquanto os outros mal apareceram na pauta. Questões como greve ou problemas nas relações de trabalho também não apareceram nas atas de reunião dessa gestão. Consideramos que a relevância assumida dos exames psicotécnicos para o Sindicato é analisador de como essa entidade se interessava pelas questões do campo de trabalho do psicólogo e não pelas reivindicações do psicólogo enquanto trabalhador.

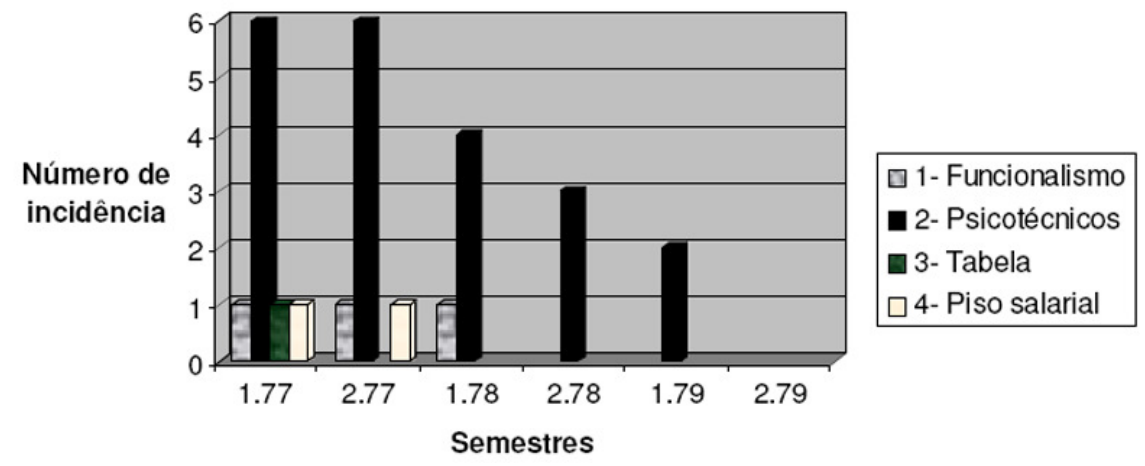

Figura 1. Reivindicações dos psicólogos discutidas em reuniões do SPESP. Frequência dos temas discutidos referentes às reivindicações de psicólogos nas reuniões da gestão 1977-1979 no SPESP. No eixo vertical encontram-se as taxas de incidência e no eixo horizontal o semestre da gestão.

Nessa década, o SPESP também ofereceu uma série de cursos de temas de Psicologia Aplicada oferecidos pela própria entidade. O Sindicato atuou como uma "escola de cursos de especialização", com cursos relativos a questões da psicologia clínica e de testes psicológicos, atividades sem uma ênfase na organização política dos psicólogos. A justificativa para tal prática foi a de arrecadar fundos e na crença de que fosse uma atividade interessante para os associados. Então, vemos que em vez de se ater às questões do trabalhador, preocupava-se mais com os exames psicotécnicos e cursos. Inclusive nas raras vezes em que se discutiu em reunião a reclamação de profissionais em relação às empresas e locais de trabalho, o Sindicato no máximo enviava uma correspondência ao chefe e assumia uma negociação numa tentativa de pacto entre chefe 
e psicólogo funcionário. O SPESP tanto evitou os conflitos que o presidente da primeira gestão do Sindicato afirmou que não havia greves de psicólogos naquela época (Cambraia, citado por Hur, 2005). O ato de buscar a conciliação e não fomentar greves geralmente favorece a perpetuação das relações instituídas, ou seja, favorece o empresário, o chefe, visto que é o empregador que tem a fala final, caso o trabalhador não reivindique radicalmente seus direitos.

No CRP a prática estava bem alinhada com o disposto na Lei 5.766/ 71 sobre a fiscalização e disciplinarização da profissão, assim, a hegemonia das práticas das comissões era sobre a fiscalização e as questões sobre a ética profissional, tal como podemos ver no gráfico 2 abaixo. Constatamos que o que caracterizou as gestões do CRP na década de 1970 foi a forte vigilância sobre as práticas dos psicólogos, para que estes não incorressem em infrações no seu exercício profissional. Inclusive o CRP tinha como funcionários fiscais que visitavam as instalações de trabalho do psicólogo, para verificar se não havia condutas "antiéticas". Consideramos que os "fiscais" faziam parte da estrutura panóptica de vigilância (Foucault, 1984) dos psicólogos, em que através dessas práticas de observação direta fiscalizava-se, controlava-se e disciplinarizava-se as práticas e o trabalho dos psicólogos. Por panóptico entendemos a formação arquitetônica, elaborada por Jeremy Bentham no século XVII, que expressa uma forma de vigilância total e serviu como modelo à construção de prisões. É planejada de uma forma circular e, a partir de um ponto central, haveria um vigilante que poderia ver todos os pontos do espaço físico. Foucault afirma que a estrutura panóptica não apenas serviu como referência às prisões, mas também para todas as instituições disciplinares, sendo o panóptico o diagrama das relações disciplinares. No caso do CRP, não havia uma instituição total que encerrava seus psicólogos, mas havia fiscais que se deslocavam para vigiá-los.

Na gestão do CRP de 1977-1980 as comissões mais discutidas em reuniões foram a de ética e a de fiscalização. É interessante notar que nos dois primeiros anos da gestão havia outras comissões discutidas, como a de tomada de contas, delegacias, publicação e credenciamento de supervisor, mas no decorrer da gestão as comissões que têm mais importância são as que discutem a ética no exercício profissional (barras de cor negra) e a fiscalização do psicólogo (barras de cor cinza). Constatamos também que nessa gestão não havia nenhuma comissão com a discussão de algum tema da Psicologia, como formação, saúde mental, trabaIho, etc., mas apenas temas operacionais para a disciplinarização do exercício profissional do psicólogo. Tal como no SPESP, a questão dos exames psicotécnicos foi amplamente discutida. 


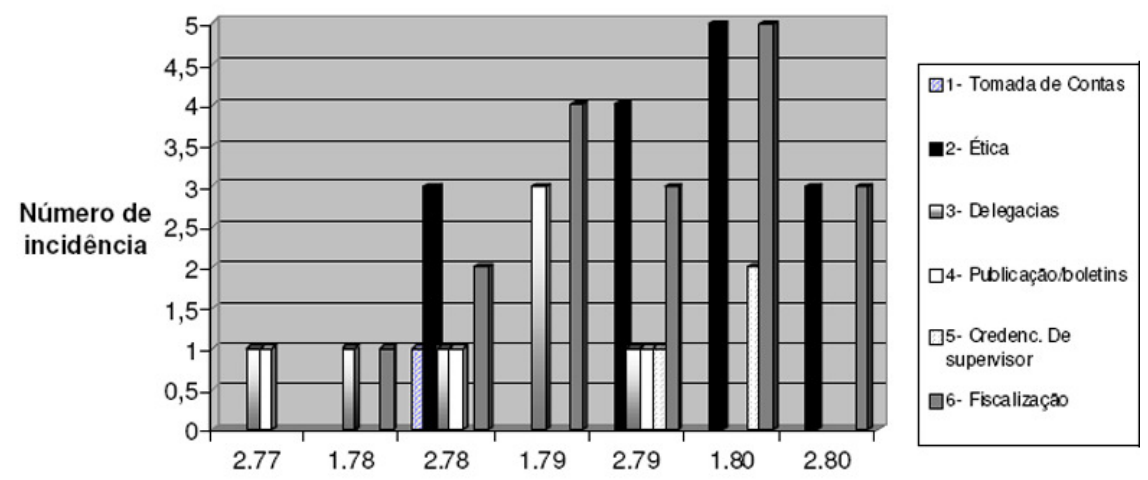

Figura 2. Comissões discutidas nas reuniões do CRP (77-80). Frequência dos temas discutidos relativos às comissões nas reuniões da gestão 1997-1980 do CRP. No eixo vertical encontram-se as taxas de incidência e no eixo horizontal os semestres da gestão.

Então nessa década as associações profissionais dos psicólogos com objetivos políticos tinham uma atuação mais "conservadora",em que priorizavam as questões organizativas e técnicas da profissão e se afastavam dos temas políticos que poderiam entrar em conflito com o Estado ditatorial. O Sindicato não assumiu o caráter de entidade organizadora dos trabalhadores e o CRP funcionou enquanto uma instituição disciplinar do Estado. Consideramos que o CRP e o SPESP adotaram uma prática eminentemente corporativista, em que as questões da sociedade brasileira foram deixadas de lado. Entretanto é nesse período que tivemos a consolidação da profissão, com a criação e instalação dessas associações profissionais.

\section{O CRP e o Sindicato na década de 1980:ruptura e politização}

No fim da década de 1970, seguindo o ressurgimento dos movimentos sociais no Brasil, um grupo de psicólogos, em sua maioria jovens, passou a se reunir para discutir a profissão. Realizaram discussões abertas que procuravam debater a profissão do psicólogo relacionada às vicissitudes do país (Silva, citado por Hur, 2005). Nelas, criticaram as práticas das entidades dos psicólogos, pois, nas lutas do funcionalismo público por melhorias nas condições de trabalho, consideravam que o Sindicato não tinha atuação. No que se referia aos casos de tortura durante a ditadura militar, as entidades de Psicologia preferiram se omitir e havia a queixa de que vários psicólogos visitavam o CRP e o SPESP e mal eram recebidos. Dessa forma, psicólogos se reuniram à parte de suas associações, fizeram discussões sobre a profissão e a realidade sociopolítica do Brasil e decidiram em 1979 montar uma chapa para concorrer nas eleições do 
Sindicato, assumindo um caráter combativo às práticas políticas das gestões das associações da década de 1970. Venceram as eleições. Esse grupo fez uma chapa para concorrer às eleições do CRP, também vencendo, e mostrou a entrada da "esquerda política" nas associações de Psicologia. Foi um acontecimento ligado ao momento histórico do Brasil, pois 1979 marcou a reabertura política do país, quando os movimentos sociais ganharam muita força, principalmente o sindical e o movimento dos metalúrgicos do $A B C$, liderado por Lula. Os psicólogos atualizaram esse fluxo instituinte e buscaram transformar suas entidades políticas, assumindo uma crítica aos assuntos político-sociais contemporâneos e passando a problematizar o caráter normalizador do próprio CRP. Nesse tópico visamos discutir as modificações nas práticas políticas empreendidas através da entrada desse novo grupo nas entidades na década de 1980.

Constatamos nas atas e nas entrevistas (Guirado, Pinheiro, Silva e Sivieri, citados por Hur, 2005) que na década de 1980 houve uma grande abertura política nas entidades de Psicologia. O Sindicato deixou de entender o psicólogo como profissional liberal para apreender o psicólogo enquanto trabalhador, enquanto empregado, pois a figura do autônomo, que um dia já representou status social, converteu-se em instabilidade empregatícia, além de não ser a situação majoritária em que o psicólogo brasileiro se encontrava. Assumiu-se assim o lema do psicólogo enquanto trabalhador. Dessa forma aproximou-se dos movimentos trabalhistas gerais, unindo-se ao movimento sindical geral: o Sindicato dos Psicólogos participou da fundação da CUT - Central Única dos Trabalhadores. Todavia, os fundadores das entidades profissionais da Psicologia, os antigos diretores do Sindicato, repudiaram essa aproximação com o movimento trabalhista geral, desfiliando-se da entidade. Os antigos diretores do CRP e do SPESP tinham grande preconceito com a CUT e com os trabalhadores manuais, defendendo assim que os psicólogos não deveriam se filiar à central sindical (Hur, 2009).

Uma outra mudança de prática está relacionada à defesa do psicólogo enquanto trabalhador. As entidades passaram a mobilizar-se a favor dos psicólogos-empregados. Elas atuaram contra as demissões em massa de psicólogos de faculdades privadas, combatendo as políticas mercadológicas de instituições como o FMU - Faculdades Metropolitanas Unidas - e o Objetivo (hoje é conhecida como UNIP - Universidade Paulista), que visavam contratar novos funcionários com salários mais baixos. As entidades se manifestaram contra essas demissões, estabelecendo negociações diretas e publicando notas em jornais de grande circulação para denunciar tal situação. Foi um movimento vitorioso, pois os novos profissionais contratados não receberam soldo inferior aos profissionais demitidos.

No CRP também houve uma mudança em relação às práticas, nas quais a ênfase nos exames psicotécnicos diminuiu e criou-se comissões 
que não existiam. Abaixo podemos ver, no gráfico 3 , em relação às comissões discutidas na gestão do CRP de 1980-1983, a ampliação do número delas, que deixaram de ser apenas comissões ligadas a assuntos operacionais, como a de ética, delegacias, publicação, credenciamento de supervisor e de fiscalização, e criou-se outras com temáticas afins da Psicologia, como psicologia organizacional, cultural, saúde e ensino, que problematizavam questões ligadas à formação e às políticas públicas. Contudo, mesmo com a criação de novas comissões, as de ética (barras de cor negra) e de fiscalização (barras de cor cinza) continuaram sendo as mais discutidas nas reuniões, ou seja, mesmo com a entrada de uma gestão mais progressista, consideramos que o CRP continuava com sua função de instituição disciplinar que tem como fim a normalização social.Desse modo o CRP assumiu um caráter ambíguo, que por um lado tinha um grupo político mais crítico, mas permaneceu com suas atribuições de fiscalização e vigilância profissional, que continuavam a ser os assuntos mais pautados em reunião.

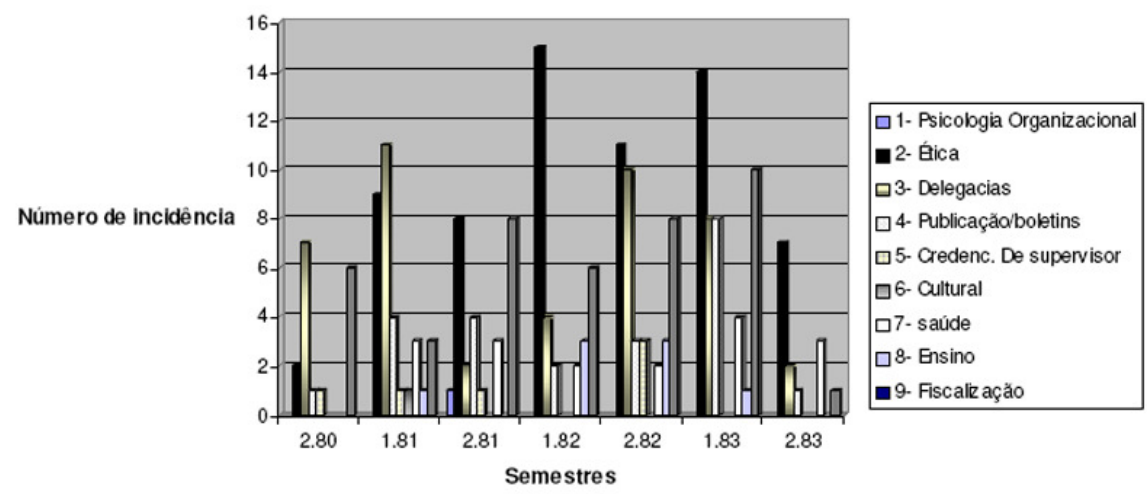

Figura 3. Comissões discutidas nas reuniões do CRP (80-83). Frequência de discussão de assuntos relativos às comissões nas reuniões da gestão 1980-1983 do CRP. No eixo vertical encontram-se as taxas de incidência e no eixo horizontal os semestres da gestão.

Entretanto, mesmo permanecendo a função disciplinar, a atuação do CRP e do SPESP se politizou, focalizando questões de lutas políticas nacionais gerais, que antes não eram discutidas, como a questão do movimento das "Diretas Já" e de uma Assembleia Constituinte cidadã. As entidades tiveram intensa participação no movimento de retorno ao direito ao voto direto e pelo fim da ditadura militar, a qual deixa de existir a partir de 1985. O fim da ditadura não resultou apenas da pressão dos movimentos sociais, mas também foi um processo negociado pela própria cúpula dos militares no fim da década de 1970, que buscou uma"tran- 
sição lenta, segura e gradual" para um governo civil (Gaspari, 2002). Com o fim da ditadura as entidades se mobilizaram nos debates referentes à nova Constituição do Brasil, no processo de votação da Assembleia Constituinte. O CRP e o Sindicato passaram a discutir as questões relevantes à nova Constituinte e lutaram por uma assembleia em que houvesse ampla participação da sociedade civil. Infelizmente a sociedade não teve seu espaço de participação, pois quem teve o poder de elaborar a Constituição foi o Congresso, que assumiu dupla função, deixando assim a sociedade civil de fora.

No âmbito do legislativo, o CRP e o Sindicato procuraram ser propositivos, criando projetos de Lei que valorizassem o psicólogo, inclusive na tentativa de mudar a lei de regência da profissão. Não conseguiram mudar a Lei, pois temiam que ao reabri-la pudesse haver o perigo de entrar emendas prejudiciais à profissão, podendo acarretar assim mais perdas do que vitórias.

Outra luta importante foi a questão do salário mínimo profissional. O Sindicato propôs uma carga horária de seis horas diárias com o piso salarial de seis salários mínimos (a campanha $6 \times 6$ ) e ao fazer pressão no Legislativo, o representante do Senado, Fernando Henrique Cardoso ${ }^{5}$, os recebeu e falou: "Eu coloco o projeto de lei em votação, mas para votar, vocês têm que tirar tanto a carga horária como tirar o valor do salário" (Sivieri, citado por Hur, 2005), ou seja alteraria substancialmente a proposta dos psicólogos, onde poderia ser votado uma carga horária alta e um piso salarial baixo. O Sindicato não aceitou tal proposta sabendo que o representante do Senado não estava interessado na luta dos trabalhadores.

Desde o fim da ditadura, o Sindicato e o CRP, mesmo não divergindo significativamente nas suas plataformas políticas, passaram a ter uma série de conflitos, em que se discutia qual era o campo de atuação e o que era específico para cada entidade (Hur, 2005). Dessa forma, as entidades passaram a organizar grandes congressos políticos, como o CONUP Congresso Nacional Unificado da Psicologia -, para ampliar o espaço de debate e deliberação. No entanto, o CONUP apenas acirrou as divergências, pois alguns segmentos do Sindicato defenderam a proposta de acabar com o Conselho, por entenderem que o CRP era uma entidade que representava a captura estatal, posicionamento que marcou a grande cisão entre Sindicato e CRP. Após o CONUP, houve um desgaste entre as associações, o abandono de muitos integrantes do CRP (Guirado, citado por Hur, 2005) e a migração dos sindicalistas para essa entidade, mantendo o caráter de esquerda política no conselho profissional.

5 Fernando Henrique Cardoso, importante sociólogo latino-americano, tornou-se presidente do Brasil por duas gestões, de 1995 a 2002. 
No fim da década de 1980, tivemos uma inflação muito alta na gestão do presidente J.Sarney, que acarretou num grande prejuízo financeiro às entidades, pois a anuidade paga pelos psicólogos no início do ano rapidamente desvalorizou e não cobriu os gastos até o fim do ano. Todas as entidades sofreram com esse quadro e o Sindicato sofreu a tal ponto que quase fechou as portas devido à questão financeira e à crise política vivida. Realizaram um plebiscito com os psicólogos para decidir se fechariam ou não o Sindicato. Aprovou-se o não fechamento, mas a diretoria ficou esvaziada, apenas tendo uma renovação de novos membros na década de 1990.

A década de 1990 foi marcada pelos Congressos Nacionais de Psicologia e muitos eventos. É nessa época que pretendem ampliar a visibilidade da profissão do psicólogo organizando grandes congressos e campanhas na mídia. Contudo não só de progressismo vive essa época, as atividades de fiscalização ainda são hegemônicas no CRP e os conflitos personalistas continuam nas entidades.

No meio dessa década, a "esquerda política" novamente rachou, o que gerou a constituição de dois grupos de "esquerda". Sivieri (citado por Hur, 2005) atribui o racha não a diferenças nas propostas políticas, mas sim a questões de caráter personalista. A tendência "Cuidar da Profissão" venceu as eleições e, desde então, se tornou hegemônica nas entidades de Psicologia. O grupo que foi derrotado acabou por se afastar das políticas da Psicologia. Desde então, até o ano de 2007, nas eleições para o CFP não houve o confronto entre duas ou mais chapas, mas apenas a candidatura de chapas únicas da tendência hegemônica.

\section{Considerações finais}

Neste artigo discutimos algumas práticas e histórias de duas associações da Psicologia com objetivos políticos: o CRP e o SPESP. Notamos que a organização dos psicólogos para a constituição de suas entidades se deu no momento de maior repressão política no Brasil, a partir do ano de 1969, após o decreto do Ato Institucional número 5, quando todos os movimentos sociais foram coibidos e proibidos. As associações trabalharam de forma corporativista, pela defesa e disciplinarização do exercício profissional, e mostraram proximidade com o regime militar, ao não participar de manifestações públicas críticas ao Estado, como a manifestação pelos direitos humanos em decorrência do assassinato do jornalista Wladimir Herzog, e concedendo o diploma de psicólogo honorário aos presidentes Médici e Geisel e seus ministros do Trabalho. Durante toda a década de 1970 as entidades de Psicologia mantiveram esse perfil de atuação, sendo instituição disciplinar atrelada ao regime militar.

No fim da década de 1970, acompanhando os movimentos sociais que trouxeram a abertura política ao país, como o movimento dos operá- 
rios, a luta pela anistia, etc., grupos de psicólogos se organizaram com o intuito de transformar suas entidades. Então, psicólogos pertencentes à esquerda política se articularam e venceram as eleições para o CRP e para o SPESP (Pinheiro e Silva, citados por Hur, 2005). Buscaram ampliar as práticas das associações, não apenas assumindo funções operacionais de fiscalização, mas também discutindo temas mais gerais relacionados ao psicólogo, como saúde, ensino e trabalho, e também assumindo proximidade às lutas sociais que se travavam na década de 1980, por exemplo, a luta pelas eleições diretas, a luta pela elaboração de uma nova Constituição para o país com participação da sociedade civil e a concepção de que o psicólogo era um trabalhador como outras classes profissionais. Então o SPESP filiou-se à CUT, o que gerou indignação dos grupos dirigentes das associações de Psicologia da década de 1970.

O movimento dos psicólogos acompanhou todo o processo de abertura política e redemocratização do país, com o fim da ditadura militar em 1985. No entanto, mesmo com posicionamentos políticos similares, é nesse período que surgem conflitos personalistas entre o CRP e o SPESP (Guirado, citado por Hur, 2005), o que gerou ataques e desgaste na relação entre ambas. Os mesmos conflitos personalistas se reeditam na década de 1990, quando a esquerda política rachou novamente nas eleições para o CFP (Sivieri, citado por Hur, 2005). No que se refere à crítica de Sivieri (Hur, 2005) sobre a divisão do grupo político de esquerda via questões personalistas e não por divergências de plataforma política, podemos hipotetizar a ocorrência de uma inversão; que em vez de ocupar a instituição ser um meio para realizar a plataforma política, ocupar e ganhar a instituição se tornou o fim, independente das semelhanças ou diferenças em relação ao projeto político. Tomar o poder se tornou o principal objetivo, denotando assim o desejo de fixação ao poder da instituição, num processo de institucionalização (uma "estatização"?), deixando o projeto do movimento social em segundo plano. Esse fenômeno é o que Bleger (1980) chama de burocratização.

Consideramos que na década de 1970 as associações profissionais da Psicologia atuaram numa conformidade política ao Estado ditatorial, denotando o compromisso histórico da Psicologia com as elites sociais do país, enquanto na década de 1980 houve uma renovação dos seus membros, que passaram a ter uma visão mais crítica e politizada sobre o Estado e o exercício da Psicologia, lutando pela restituição da democracia e pela ampliação da participação política da sociedade, por um lado atualizando assim o imaginário da transformação social do país, mas, por outro, ainda mantendo o caráter disciplinar de instituição normalizadora.

Essa faceta paradoxal do CRP, de manter o caráter de instituição disciplinar, mesmo com a gestão a partir de um viés da esquerda política, nos faz pensar que as suas atribuições previstas por lei se mantêm e têm 
primazia nas práticas políticas, mesmo quando grupos críticos a essas práticas gerem a entidade. E foi o que ocorreu, quando o grupo de esquerda que surge no fim da década de 1970, tal como um movimento social, atrela-se à estrutura disciplinar da entidade. É como se o movimento social ao ocupar tal estrutura sofresse a captura do Estado.Tal fenômeno é semelhante ao processo de institucionalização que a esquerda política sofre quando passa a ocupar instâncias burocratizadas como o Estado e o partido (Przeworski, 1989). Pois por mais que se altere a ideologia política e a concepção sobre o social e a profissão, o CRP continuou a ter a função de fiscalização da profissão, produzindo normas que devem ser obedecidas e reproduzidas, ou seja, por mais que haja uma ideologia progressista e crítica, a governamentalidade (Foucault, 1979) permanece opressiva. Consideramos assim, a partir do pensamento foucaultiano, que o CRP é uma instituição disciplinar, que assume função de normalização da profissão, em que articula poder jurídico, no sentido de ser autarquia do Estado que regula a profissão, e saber disciplinar, pois é instituição que pauta suas decisões e constrói suas normas a partir da produção e reprodução dos saberes psicológicos. Dessa forma podemos afirmar que o CRP se localiza na dobra, na intersecção, entre poder jurídico e saber disciplinar; é instituição disciplinar por excelência. Então, do encontro entre movimento social de psicólogos e instituição disciplinar temos a constituição de um lugar paradoxal, numa tensão entre um polo progressista e outro polo capturante. A gestão nasceu de um movimento social de base dos psicólogos, mas ocupou uma instituição disciplinar ligada ao Estado. Ou seja, consideramos que a gestão de esquerda no CRP carregava dentro de si uma contradição entre Estado e movimento social, entre Aparelho de Captura e máquina de guerra (Deleuze \& Guattari, 1997). É como se na medida em que esse movimento apropriava-se da estrutura da autarquia e passava a legislar e normatizar o exercício profissional, passava a exercer o poder do Estado, a legislar como o "soberano", o "rei jurista". Dessa maneira a máquina de guerra atrelava-se ao Estado, ao Aparelho de Captura, de uma forma paradoxal, ora produzindo fissuras no instituído, instaurando novas práticas, e ora reproduzindo o status quo, disciplinando e fiscalizando o exercício profissional. Essa crítica que desenvolvemos converge com a proposição do filósofo Gilles Deleuze (1988), que afirma que não existe um Estado de esquerda, pois as práticas do Estado em si são conservadoras, capturantes, codificadoras e levam mais a uma estática do que ao movimento. Deleuze afirma então que não há Estado de esquerda, havendo no máximo um Estado permeável a algumas práticas de esquerda. Nesse caso, como podemos pensar uma nova governamentalidade para o CRP que supere e transforme o modelo de instituição disciplinar e de vigilância? Será que sempre haverá uma captura do movimento social via lógica do Estado? Será que o CFP, atualmente com seu discurso de compromisso social da Psicologia e a ênfase 
na discussão das políticas públicas, rompe com a lógica de instituição disciplinar? Essas são perguntas que merecem novas pesquisas. Entretanto, no período estudado, com a entrada da esquerda política nas entidades deparamo-nos com o paradoxo do CRP; por mais progressista que seja sua diretoria e suas realizações, ainda se mantêm ações disciplinares e reprodutoras de Estado.

Politics of the Psychology: histories and practices of the professional associations (CRP and SPESP) of São Paulo, between the dictatorship and the democratization of the country

Abstract:The aim of our study is to discuss the history and practices of the professional associations of the psychology between the military dictatorship and the process of democratization of the country. We interviewed six former-participants of these entities and we did the documentary analysis of 1076 minutes of the CRP and of the SPESP. We note that in the beginning there was a political alignment of the entities with the military dictatorship, when they refused to participate in critical movements to the military government and when they awarded a prize with the title of honorary psychologist to representatives of the dictatorship. At the end of the 1970s, when social movements reappear in Brazil, an opposition with left-wing ideology gets organized and wins the elections in the two entities. They assume their political character and contribute to social movements in the country, as the foundation of the CUT and the movement of "Diretas Já".

Keywords: History of psychology. Military dictatorship. Professional associations. Political psychology.

Politiques de la Psychologie: des histoires et des pratiques des associations professionnelles (CRP et SPESP) à São Paulo, entre la dictature et la démocratisation du pays

Résumé: L'objectif de notre étude est de discuter l'histoire et les pratiques des associations professionnelles avec des objectifs politiques de la psychologie entre le régime militaire et le processus de démocratisation du pays. Dans la recherche, on a interviewé six ex-participants des conseils de ces entités et fait l'analyse documentaire de 1076 minutes du CRP et SPESP. Nous avons constaté qu'au début il y avait un alignement politique des entités avec la dictature militaire, quand ils ont refusé de 
participer à des mouvements qui critiquent le régime et quand des représentants de la dictature militaire ont été faits psychologue honoraire par eux. À la fin des années 1970, une période dans laquelle les mouvements sociaux réapparaissent au Brésil, une opposition avec une idéologie de gauche s'organise et remporte les élections dans les deux entités. Ils assument plus de caractère politique et contribuent avec des mouvements sociaux dans le pays, comme la fondation de la CUT et le mouvement "diretas já".

Mots-clés: Histoire de la psychologie.Dictature militaire. Associations professionnelles. Psychologie politique.

\section{Políticas de la Psicología: historias y prácticas de las asociaciones profesionales (CRP y SPESP) de São Paulo, entre la dictadura y la redemocratización del país}

Resumen: El objetivo de nuestro trabajo es discutir la historia y las prácticas de las asociaciones profesionales con objetivos políticos de la Psicología entre el régimen militar y el proceso de redemocratización del país. En la investigación entrevistamos seis ex-participantes de las entidades e hicimos el análisis documental de 1076 actas del CRP y del SPESP. Constatamos que en el comienzo hubo un alineamiento político de las entidades con la dictadura militar. En el fin de la década de 1970, período en que los movimientos sociales resurgen en Brasil, una oposición con ideología de izquierda se organiza y vence las elecciones en las dos entidades. Asumen mayor carácter político y contribuyen con los movimientos sociales del país, como la fundación de la CUT y el movimiento de las "Diretas Já".

Palavras clave: Historia de la Psicología.Dictadura militar. Asociaciones profesionales. Psicología política.

\section{Referências}

Antunes, M. A. M. (1998). A Psicologia no Brasil: leitura histórica sobre sua constituição. São Paulo: Unimarco.

Bardin, L. (1977). Análise de conteúdo. Lisboa: Edições 70. 
Bleger, J. (1980). Temas de Psicologia: entrevistas e grupos. São Paulo: Martins Fontes.

Bock, A. M. B. (1991). Pensando a profissão de psicólogo ou Eu, caçador de mim. Dissertação de Mestrado, Pontifícia Universidade Católica de São Paulo, São Paulo.

Bock, A.M.B. (1999). Aventuras do Barão de Munchhausen na Psicologia. São Paulo: EDUC.

Conselho Regional de Psicologia - 6a. região. (1994). Uma profissão chamada psicologia:CRP-06, 20 anos. São Paulo: Autor.

Deleuze, G. (1988). Abecedário. (Documentário).

Foucault, M. (1979). Microfísica do poder. Rio de Janeiro: Graal.

Foucault, M. (1984). Vigiar e punir. Petrópolis, RJ: Vozes.

Foucault, M. (1999). Em defesa da sociedade: curso dado no Collège de France (1975-1976). São Paulo: Martins Fontes.

Gaspari, E. (2002). A ditadura envergonhada. São Paulo: Cia das Letras.

Hur, D. U. (2005). Políticas da Psicologia de São Paulo: as entidades de classe durante o período do regime militar à redemocratização do país. Dissertação de Mestrado, Instituto de Psicologia, Universidade de São Paulo, São Paulo. Recuperado em 24 de junho de 2009, de www.teses.usp.br/teses/disponiveis/ 47/47134/tde-11072006-224031/

Hur, D. U. (2007). A Psicologia e suas entidades de classe: histórias sobre sua fundação e algumas práticas no Estado de São Paulo nos anos 70. Psicologia Política, 13(1), Recuperado em 24 de junho de 2009, de www.fafich.ufmg.br/ $\sim$ psicopol/seer/ojs/viewarticle.php?id=17\&layout=html\&mode=preview.

Hur, D. U. (2009). O surgimento da esquerda nas entidades profissionais dos psicólogos de São Paulo, CRP-06 e SPESP, no período da abertura política brasileira. Mnemosine, 5(1), 126-145. Recuperado em 03 de maio de 2010, de http:/ /www.mnemosine.cjb.net/mnemo/index.php/mnemo/article/viewFile/348/ 557

Lourau, R. (2004). René Lourau:analista Institucional em tempo integral.In S. Altoé (Org.), São Paulo: HUCITEC.

Macedo, J. R., \& Maestri, M. (2004). Belo Monte: uma história da guerra de canudos. São Paulo: Expressão Popular. 
Mann, P. (1983). Métodos de investigação sociológica. Rio de Janeiro: Zahar.

Massimi, M. (1990). História da psicologia brasileira: da época colonial até 1934. São Paulo: Editora Pedagógica e Universitária.

Massimi, M., \& Guedes, M. C. (2004). História da Psicologia no Brasil: novos estudos. São Paulo: Educ \& Cortez.

Mello, S. L. (1975). Psicologia e profissão em São Paulo. São Paulo: Ática.

Pessotti, I. (1998). Notas para uma História da Psicologia no Brasil. In Conselho Federal de Psicologia, Quem é o psicólogo brasileiro? (pp. 17-31). São Paulo: Edicon.

Przeworski, A. (1991). Capitalismo e social-democracia.São Paulo:Companhia das Letras.

Rodrigues, R. N. (1939). A loucura epidêmica de Canudos. In As Colletividades anormaes (pp. 50-77). Rio de Janeiro: Civilização Brasileira.

Sindicato dos Psicólogos no Estado de São Paulo. (1975). Livro de Atas n. 1. (Ata 23 de 03 de novembro de 1975)

Sindicato dos Psicólogos no Estado de São Paulo. (1987). Psicólogo: informações sobre o exercício da profissão. São Paulo: Cortez.

Sindicato dos Psicólogos no Estado de São Paulo, \& Conselho Regional de Psicologia, 6a. região. (1984). O perfil do psicólogo no estado de São Paulo. São Paulo: Cortez.

Skidmore, T. E. (1998). Uma história do Brasil. São Paulo: Paz e Terra. 
Domenico Uhng Hur, Professor Adjunto da Universidade Federal de Goiás. Psicólogo, mestre e doutor em Psicologia Social pela Universidade de São Paulo, com realização de doutorado-sanduíche na Universitat Autònoma de Barcelona - UAB. Endereço para correspondência:Universidade Federal de Goiás, Faculdade de Educação, Rua 235 s/n, Setor universitário, Goiânia, GO, Brasil, CEP 74605-050. Endereço eletrônico: Domenicoh@usp.br

Recebido: $16 / 10 / 2010$

Aceito: $22 / 06 / 2011$ 